\title{
Analysis of the astray/robo2 Zebrafish Mutant Reveals that Degenerating Tracts Do Not Provide Strong Guidance Cues for Regenerating Optic Axons
}

\author{
Cameron Wyatt, ${ }^{1 \star}$ Anselm Ebert, ${ }^{1 \star}$ Michell M. Reimer, ${ }^{1}$ Kendall Rasband, ${ }^{2}$ Melissa Hardy, ${ }^{2}$ Chi-Bin Chien, ${ }^{2}$ \\ Thomas Becker, ${ }^{1 * *}$ and Catherina G. Becker ${ }^{1 * *}$ \\ ${ }^{1}$ Centre for Neuroregeneration, School of Biomedical Sciences, University of Edinburgh, Edinburgh EH16 4SB, United Kingdom, and ${ }^{2}$ Department of \\ Neurobiology and Anatomy, University of Utah School of Medicine, Salt Lake City, Utah 84132
}

\begin{abstract}
During formation of the optic projection in astray/robo2 mutant zebrafish, optic axons exhibit rostrocaudal pathfinding errors, ectopic midline crossing and increased terminal arbor size. Here we show that these errors persist into adulthood, even when robo2 function is conditionally reduced only during initial formation of the optic projection. Adult errors include massive ectopic optic tracts in the telencephalon. During optic nerve regeneration in astray/robo2 animals, these tracts are not repopulated and ectopic midline crossing is reduced compared with unlesioned mutants. This is despite a comparable macrophage/microglial response and upregulation of contactin1 $a$ in oligodendrocytes of entopic and ectopic tracts. However, other errors, such as expanded termination areas and ectopic growth into the tectum, were frequently recommitted by regenerating optic axons. Retinal ganglion cells with regenerating axons reexpress robo 2 and expression of slit ligands is maintained in some areas of the adult optic pathway. However, slit expression is reduced rostral and caudal to the chiasm, compared with development and ubiquitous overexpression of Slit2 did not elicit major pathfinding phenotypes. This shows that (1) there is not an efficient correction mechanism for large-scale pathfinding errors of optic axons during development; (2) degenerating tracts do not provide a strong guidance cue for regenerating optic axons in the adult CNS, unlike the PNS; and (3) robo2 is less important for pathfinding of optic axons during regeneration than during development.
\end{abstract}

\section{Introduction}

In adult fish and amphibians, severed optic axons are capable of correctly growing through their original pathways and of functional target reinnervation (Becker and Becker, 2007). Given that the distances regenerating axons cover are much greater than during development and that regenerating axons cannot navigate by fasciculation with existing axons, as is the case for developing axons (Pittman et al., 2008), the question arises how precise navigation and target reinnervation is accomplished. Answering this question may have wider consequences in the context of achieving directional axonal regeneration in the CNS of mammals, in which axon regrowth is currently difficult to induce (Chaudhry and Filbin, 2007).

Mechanical or molecular interactions with the denervated brain tracts could guide regenerating axons. For example, in the

Received July 23, 2010; revised Aug. 20, 2010; accepted Aug. 26, 2010.

This work was supported by the National Institutes of Health (R01 EY12873 to C.-B.C.), the Deutsche Forschungsgemeinschaft (Grant Be 1654/10 to C.-G.B.), a Biotechnology and Biological Sciences Research Council Doctoral Training Grant studentship to C.W., and the Wellcome Trust (Grant WT078052 to T.B. and C.-G.B.). We thank Dr. Herwig Baier for transgenic fish, and Drs. David Price and Thomas Theil for critically reading the manuscript, and Sudeh Riahi for expert fish care.

${ }^{*}$ C.W. and A.E. contributed equally to this work.

**T.B. and C.G.B. contributed equally to this work.

Correspondence should be addressed to either Catherina G. Becker or Thomas Becker, Centre for Neuroregeneration, School of Biomedical Sciences, University of Edinburgh, The Chancellor's Building, 49 Little France Crescent, Edinburgh EH16 4SB, United Kingdom. E-mail: catherina.becker@ed.ac.uk or thomas.becker@ed.ac.uk.

DOI:10.1523/JNEUROSCI.3846-10.2010

Copyright $\odot 2010$ the authors $\quad 0270-6474 / 10 / 3013838-12 \$ 15.00 / 0$ regenerating peripheral nervous system of mice, denervated Schwann cell tubes provide mechanical guidance for regenerating axons (Nguyen et al., 2002). At the same time, Schwann cells upregulate a number of axon growth promoting molecules (Oudega and Xu, 2006), which is also true for oligodendrocytes in the fish CNS (Stuermer et al., 1992). Alternatively, regenerating optic axons may actively read specific molecular cues, similar to those that guide developing pioneer axons to their targets (Becker and Becker, 2007). It is difficult to distinguish between these mechanisms in vivo, because degenerating tracts always overlap with the appropriate trajectories of regenerating axons. We decided to address this problem using the zebrafish astray mutant (Karlstrom et al., 1996). In this mutant, ectopic optic tracts are formed in a stochastic manner during development. If these tracts acted as nonspecific guidance cues for regenerating axons they would divert some of the regenerating optic axons from their correct trajectories.

Astray $^{\text {ti272z }}$ is a functional null mutation for robo2 (Fricke et al., 2001), a receptor for repellent extracellular matrix (ECM) cues of the Slit class (Dickson and Gilestro, 2006). These mutants show pathfinding (rostrocaudal pathfinding errors, ectopic midline crossing) and termination errors (increased terminal arbor sizes) of optic axons during development (Fricke et al., 2001; Campbell et al., 2007), which are similar to those in slit or robodeficient mice (Plump et al., 2002; Plachez et al., 2008). Timelapse analysis indicates that optic axons in astray mutants, in contrast to wild-type axons, do not correct errors during growth 
across the chiasm (Hutson and Chien, 2002). However, the longterm fate of aberrantly growing axons in astray mutants has not been determined. Moreover, similar to other ECM molecules (Becker and Becker, 2002; Becker et al., 2004), Robo/Slit guidance could be important for regenerating optic axons.

Our analysis shows that ectopic tracts are not a preferred guidance cue for regenerating optic axons, despite a comparable cellular and molecular reaction to deafferentation in entopic and ectopic optic tracts. Dramatic pathfinding errors found in optic axons of adult astray (robo2) mutants are strongly reduced after regeneration. There are fewer expression domains of slits in adults than in embryos and overexpression of Slit2 does not affect axon regrowth. This indicates that Slit/Robo2 interactions are less important during regeneration than during development.

\section{Materials and Methods}

Animals. All fish are kept and bred in our laboratory fish facility according to standard methods (Westerfield, 1989) and all experiments have been approved by the British Home Office. We used homozygous astray ${ }^{t i 272 z}$ mutants (Karlstrom et al., 1996; Fricke et al., 2001), which are adult viable, crossed with $\operatorname{Tg}$ (pou4f3:gap43-GFP) ${ }^{\text {s356t }}$ (Xiao et al., 2005) transgenic fish to visualize the optic projection in living larvae. We also used the $\operatorname{Tg}(\text { hsp70l:slit2-EGFP })^{\text {rw015d }}$ line for slit2-GFP fusion protein overexpression (Yeo et al., 2004) and $\mathrm{Tg}\left(\right.$ hsp70l:mcherry) ${ }^{\mathrm{zc} 62}$ control; both transgenes use the $1.5 \mathrm{~kb}$ hsp $70 \mathrm{l}$ promoter (Halloran et al., 2000).

Analysis of living larvae. To assess the presence of an ectopic projection to the telencephalon, 5-d-old larvae were anesthetized in $0.01 \%$ aminobenzoic acid ethylmethylester (MS222) (Sigma) and the presence of axons in the telencephalon was assessed under a stereomicroscope equipped with fluorescence detection (SV8, Zeiss). Subsequently, larvae were returned to tank water and raised to adulthood (older than 3 months of age).

Analysis of heat-shocked larvae. Hsp70l:mCherry or hsp70l:slit2-EGFP embryos were heat shocked for $1 \mathrm{~h}$ in a $38^{\circ} \mathrm{C}$ water bath at $32 \mathrm{~h}$ postfertilization (hpf), allowed to recover at $28.5^{\circ} \mathrm{C}$, then fixed at $48 \mathrm{hpf}$. Embryos were mounted in agarose, and the right eye was injected with $\mathrm{DiO}\left(3,3^{\prime}\right.$-dioladecyloxacarbocyanine perchlorate) or DiI $\left(1,1^{\prime}\right.$-dioctadecyl-3,3,3',3'-tetramethylindocarbocyanine perchlorate), respectively (Hutson and Chien, 2002). Embryos were imaged laterally using a 488 or $568 \mathrm{~nm}$ laser for excitation and a $20 \times$ air or $40 \times$ water objective to capture a $z$-stack of axon labeling and a differential interference contrast image of the embryo.

Adult optic nerve lesion and heat shocks. Optic nerve crush lesion was performed as described previously (Becker et al., 2000). Briefly, fish were deeply anesthetized by immersion in $0.033 \%$ MS222. The left eye was gently rotated out of its socket and the exposed opaque optic nerve was crushed with a pair of watchmaker's forceps. A clear stripe across the nerve indicated successful crush. Fish were revived in tank water and allowed to survive for up to 4 weeks postlesion. For heat shock application, lesioned animals underwent daily heat shocks beginning at $3 \mathrm{~d}$ postlesion until $21 \mathrm{~d}$ postlesion, when optic nerve tracing took place. Tank water was heated from $25^{\circ} \mathrm{C}$ to $39^{\circ} \mathrm{C}$, remained at this elevated temperature for at least $1 \mathrm{~h}$ and was allowed to cool down again. This procedure has previously been shown to elicit gene expression from the hsp70l promoter in adult fish (our unpublished observations) (Lee et al., 2005).

Immunohistochemistry. Antibodies for Tenascin-R (Becker et al., 2004), tyrosine hydroxylase (mab318, Millipore), GFP (A 11122, Invitrogen), and serotonin (S5545, Sigma) were used for immunofluorescent detection on $50 \mu \mathrm{m}$ floating sections as described previously (Reimer et al., 2008) and analyzed by confocal microscopy. Labeling intensity was measured by calculating the mean pixel brightness for a defined area of the dorsal tectum for wild-type and astray animals using ImageJ (http://rsbweb.nih.gov/ij/).

In situ hybridization and combination with immunohistochemistry. Probes for robo2, slit1a (Campbell et al., 2007), slit1b (Hutson et al., 2003), slit2, slit3 (Yeo et al., 2001) and contactin1a (Schweitzer et al.,
2007) have been described. Nonradioactive in situ hybridization was performed on cryosections ( $14 \mu \mathrm{m}$ in thickness) from fresh frozen eyes and brains with digoxigenin-labeled probes as described previously (Becker et al., 2000). Combination of contactin1a in situ hybridization with immunohistochemistry for macrophages/microglial cells with the 4C4 antibody (Becker and Becker, 2001) was performed sequentially as described previously (Schweitzer et al., 2007).

Analysis of the adult optic projection. Labeling of the optic projection with biocytin (Sigma) has been described (Becker et al., 2000). Briefly, fish were deeply anesthetized and the entire optic nerve was cut followed by immediate application of a piece of gelatin foam soaked with the tracer. The tracer was allowed to be transported in the axons for $2.5 \mathrm{~h}$. Fish were transcardially perfused with $2 \%$ glutaraldehyde/ $2 \%$ paraformaldehyde and brains were cross-sectioned on a vibrating blade microtome (Microm) at a thickness of $50 \mu \mathrm{m}$. Biocytin was detected with the $\mathrm{ABC}$ kit (Vectastain) and sections were counterstained with Neutral Red (Sigma). Ectopic tracts were scored when bundles of straight parallel axons were detected. Commissures and tracts were scored as containing optic axons, when at least two (posterior commissure) or three (optic chiasm) axonal profiles per section were detectable, to discount low levels of spontaneous misrouting in wild-type animals. Variability of measurements is given as SEM.

Morpholino experiments. We used a splice blocking morpholino for robo2 (5'-TAAAAAGTAGCGCAACTCACCATCC- $\left.3^{\prime}\right)$ that targets the exon1-intron 1 splice donor site, injecting $1 \mathrm{nl}$ of a $1 \mathrm{~mm}$ morpholino solution per embryo (Becker et al., 2003). For comparison, a nonactive control morpholino was injected (GCTCCGCCACATCACAACACGCGC) (Becker et al., 2003). For PCR analysis of aberrant splicing, RNA was extracted from pooled tissue of 15 larvae per time point using the RNeasy Mini Kit (Qiagen). Reverse transcription, using random primers (Promega), was performed with the SuperScript III kit (Invitrogen). The following primers were used to amplify the appropriately and aberrantly spliced sequence in PCR: robo2ex1 forward (AAACGTGTTCTGGGGTTGAG), binding in exon 1, 31 bp upstream of the start codon; and robo2ex2 reverse (CAGATCGGAGGGGTGTTCTA), binding in exon 2. To determine whether the morpholino phenocopies the astray mutant during early development of the optic projection, DiI was applied to the whole optic nerve of 3- to 4-d-old robo2 morpholinoinjected larvae as described previously (Becker et al., 2003).

\section{Results}

Using adult astray mutants we aimed to answer the following questions. (1) Is there a mechanism to correct developmental pathfinding errors of optic axons in the long term? (2) Are degenerating tracts used as a nonspecific guidance cue for regenerating optic axons in the adult brain? (3) Does robo2 play a role for guidance of regenerating optic axons?

\section{Developmental targeting errors persist in adult astray mutants}

To determine whether there is an efficient mechanism for correcting developmental targeting errors of optic axons, we analyzed whether developmental misprojections are retained in adult astray mutants. Astray embryos show variability in the penetrance of the axon misrouting phenotype. To enrich our sample for animals with clear developmental misprojections, astray mutants were crossed into a pou4f3:GFP (previously, brn3c:GFP) background, which labels optic axons in living larvae. Thus, we were able to select larvae for raising that had a strong phenotype. This was judged based on the presence of ectopic telencephalic projections, which were detected in $66.9 \pm 7.10 \%(n=92$ larvae $)$ of the larvae (Fig. $1 A, B$ ). The fact that a third of the mutants did not have a telencephalic projection suggests that tract formation in the telencephalon is a stochastic event, and not because of optic axons consistently following secondary cues in the absence of Robo2 signaling. 
A
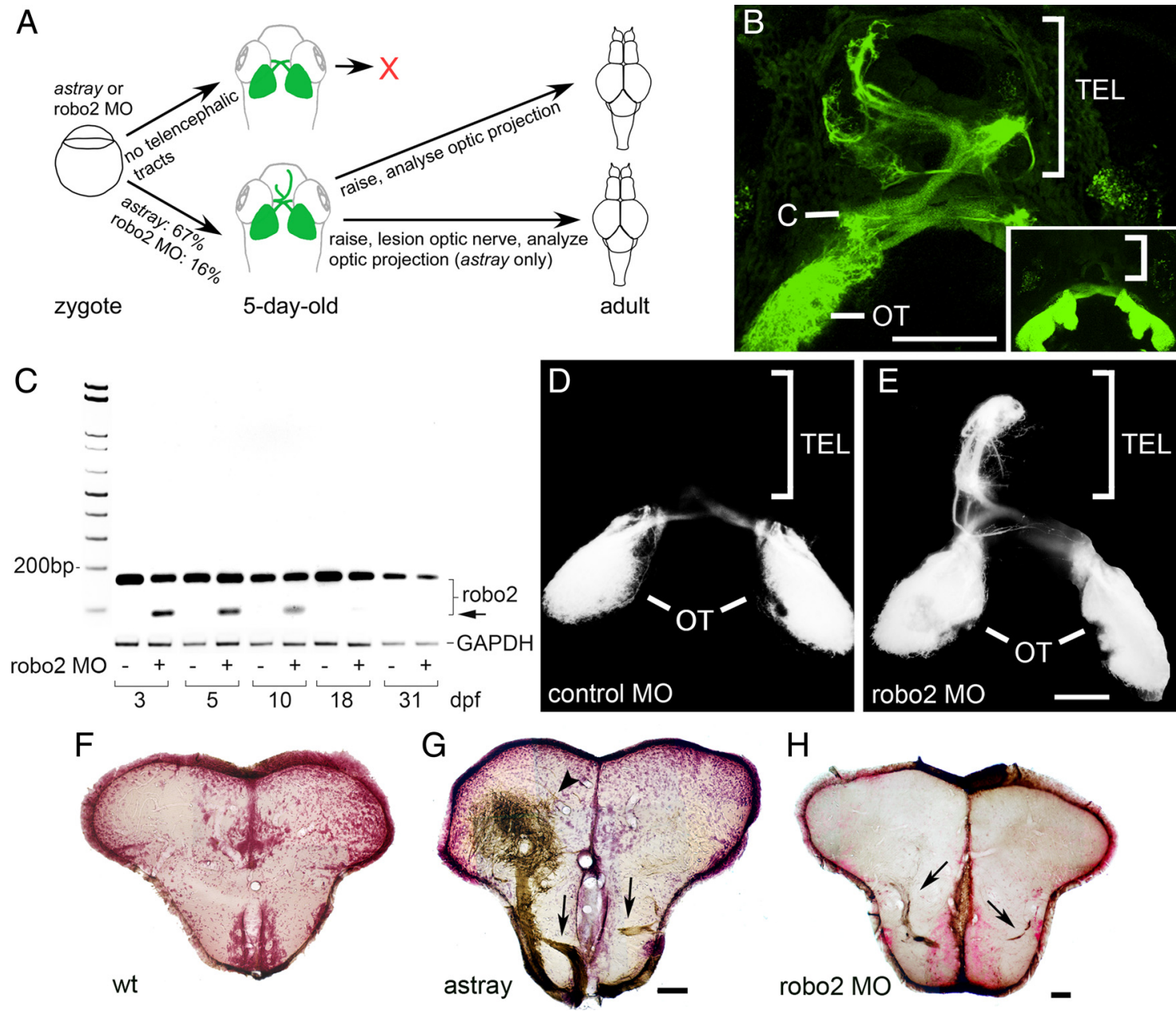

Figure 1. Pathfinding errors in the optic projection are retained in adults in astray mutants and in robo2 morphants. $A$, Experimental paradigm. Living 5-d-old larvae were preselected for the presence of aberrant telencephalic optic tracts and raised for adult experiments as indicated. $\boldsymbol{B}$, Dorsal views are shown (rostral is up). Living astray larvae were selected according to the presence of GFP-positive optic axons in the telencephalon (TEL). Inset shows a wild-type projection without telencephalic tracts. (C, chiasm; $0 \mathrm{~T}$, optic tectum). Brightly labeled neuromasts have been removed from the projection for clarity. C, PCR analysis of robo2 mRNA expression with and without robo2 splice-blocking morpholino (M0). The morpholino reduces the abundance of the wild-type transcript and an erroneous transcript (arrow) becomes detectable through at least $10 \mathrm{dpf}$. Glyceraldehyde-3-phosphate dehydrogenase is used as an internal standard. D, E, Dorsal views of Dil-traced optic projections (rostral is up) indicate astray-like pathfinding errors in robo2 morpholino-injected (E), but not in control morpholino-injected (D) 5-d-old larvae. The ectopic projection to the telencephalon is mainly unilateral. $\boldsymbol{F}-\boldsymbol{H}$, Photomicrographs show optic axons (brown) in cross sections of the adult telencephalon (counterstained in red); dorsal is up. Ectopic tracts of optic axons (arrows in $\boldsymbol{G}, \boldsymbol{H}$ ) are present in the telencephalon of astray $(\boldsymbol{G})$ and robo2 morphant $(\mathrm{MO})$ animals $(\boldsymbol{H})$, but not in wild type $(\boldsymbol{F})$. The arrowhead in $\boldsymbol{G}$ indicates a dense termination area of ectopic optic axons in the dorsal telencephalon. Scale bars: $\boldsymbol{B}, 100 \mu \mathrm{m}(250 \mu \mathrm{m}$ for inset); $\boldsymbol{D}, \boldsymbol{E}, 100 \mu \mathrm{m} ; \boldsymbol{F}, \boldsymbol{G}, 200 \mu \mathrm{m} ; \boldsymbol{H}, 100 \mu \mathrm{m}$.

Errors in rostrocaudal pathfinding

Optic projections of adults were traced unilaterally to reveal midline crossing of optic axons. Wild-type animals never showed any axons in the telencephalon ( $n=12$ animals) (Fig. $1 F$ ). In 14 of 15 astray mutants with a confirmed ectopic larval telencephalic projection, such a projection was also found at the adult stage (Fig. $1 G)$. In these fish, ectopic tracts entered the telencephalon ventrally, rostral to the chiasm. Fascicles of optic axons often recrossed the midline in the ventral telencephalon. Some tracts projected all the way to the olfactory bulb. At the end of fascicles, dense arborization fields were found, particularly in the dorsal telencephalon. In the one fish without optic axons in the adult telencephalon, telencephalic tracts detected at the larval stage could have either originated exclusively from the unlabeled eye or been reduced during later development.

Caudally misprojecting ectopic tracts of optic axons, often seen in astray larvae (Fricke et al., 2001), were never observed in wild-type adults (Fig. $2 \mathrm{~A}$ ), but were present in the tegmentum at the level of the caudal tectum in astray adults ( 4 of 15 animals; Fig.
$2 B)$. These tracts crossed the midline in the tegmentum and axons grew dorsally to terminate in superficial layers of the tectum. Overall, the observations that 14 of 15 larvae preselected for the presence of ectopic optic tracts in the telencephalon retained these as adults and that several of these animals displayed other ectopic tracts suggest that astray mutants that had ectopic tracts as larvae usually retained them into adulthood.

\section{Aberrant midline crossing}

In addition to midline crossing of ectopic telencephalic and tegmental tracts, we observed ectopic midline crossing of optic axons in the posterior commissure in astray adults (12 of 15 animals), but never in wild type ( $n=12$ animals; Fig. $2 L, M)$. Ectopic crossing in the posterior commissure is extremely common in astray larvae (Fricke et al., 2001; K.R. and C.-B.C., unpublished observations). The tectum is innervated exclusively contralaterally as a continuous layer in all wild-type animals (Fig. $2 C)$. In contrast, we observed blocks of innervation in the ipsilateral tectum of all astray mutants (15 of 15 animals; Fig. 2D). In 


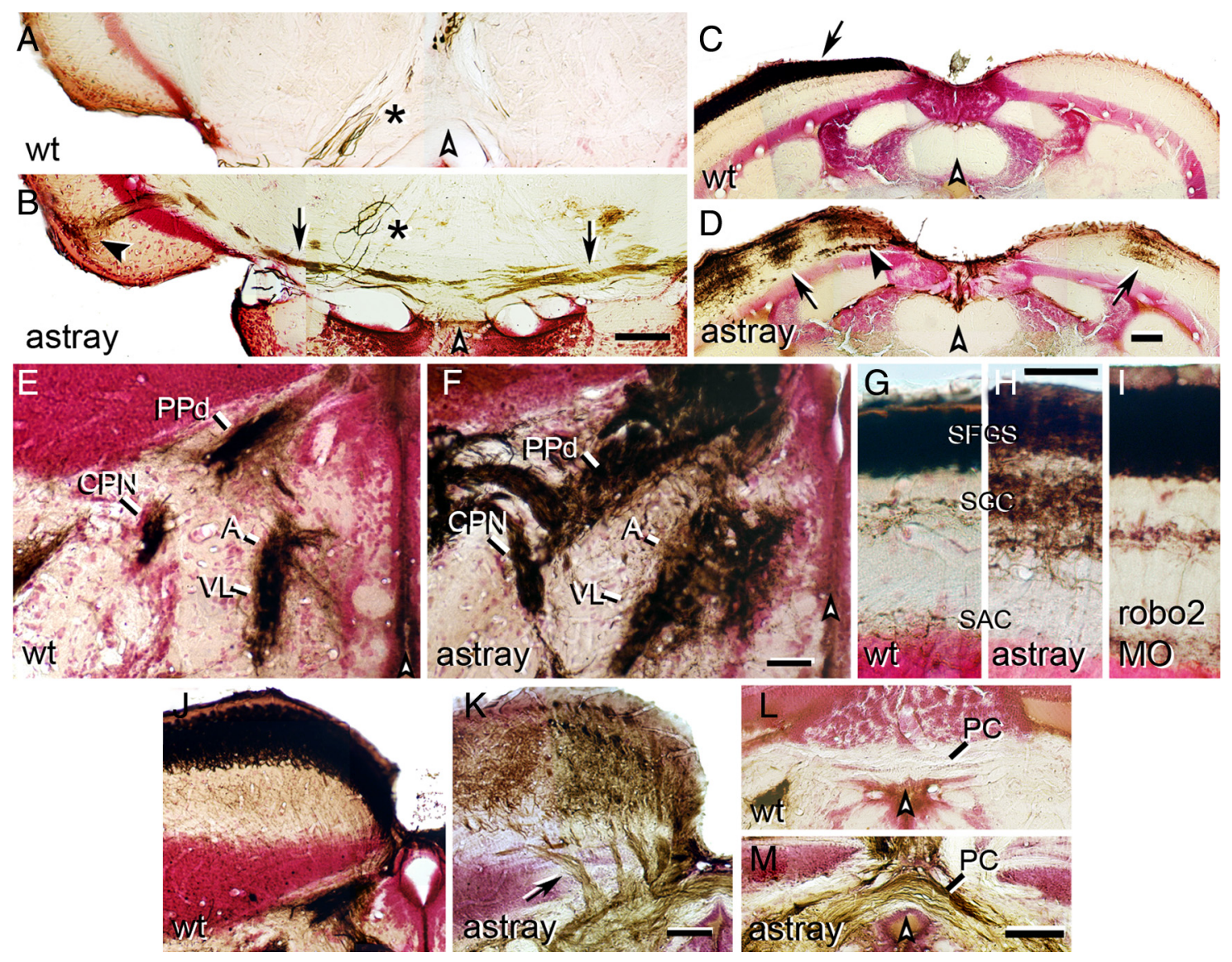

Figure 2. Aberrations of the optic projection in adult astray mutants and robo2 morphants. Photomicrographs show optic axons (brown) in cross sections of the adult brain (counterstained in red); dorsal is up. White arrowheads indicate brain midline. $\boldsymbol{A}, \boldsymbol{B}$, Ectopic optic tracts ( $\boldsymbol{B}$, arrows) in the tegmentum of astray mutants cross the midline and terminate in the ipsilateral tectum (black arrowhead). No ectopic tracts are present in wild-type animals $(\boldsymbol{A})$. Asterisks $(\boldsymbol{A}, \boldsymbol{B})$ indicate large diameter axons of the oculomotor nucleus that are always inadvertently retrogradely traced from the eye muscles. $\boldsymbol{C}, \boldsymbol{D}$, In wild-type fish $(\boldsymbol{C})$, optic axons cover the entire contralateral tectum only (arrow in $\boldsymbol{C}$. In astray mutants $(\boldsymbol{D})$ the contralateral and ipsilateral tectal halves are innervated in ocular dominance column-like patches ( $\boldsymbol{D}$, arrows). Note deep axons growing into the tectum in astray mutants (black arrowhead in $\boldsymbol{D}) . \boldsymbol{E}, \boldsymbol{F}$, Innervation of the $(\mathrm{PNN}$, the anterior (A) and ventrolateral thalamus (VL), as well as the dorsal part of the periventricular pretectal nucleus (PPd) is expanded in astray (F) compared with wild-type (E). $\mathbf{G}-\mathbf{I}$, Innervation of tectal layers is expanded in astray mutants $(\boldsymbol{H})$, but not in robo2 morpholino-treated animals $(\boldsymbol{I})$ compared with wild-type (G). SFGS, Stratum fibrosum et griseum superficiale; SGC, stratum griseum centrale; SAC, stratum album centrale. $J, K$, In astray mutants $(\boldsymbol{K})$, but not in wild-type animals $(J)$, optic axons enter the tectum in several individual deep fascicles (arrow in $\boldsymbol{K}$ ). $\boldsymbol{L}, \boldsymbol{M}, 0$ ptic axons cross in the posterior commissure $(\mathrm{PC})$ in astray $(\boldsymbol{M})$, but not in wild-type fish (L). Scale bars: $A, B, E-I, 50 \mu \mathrm{m} ; \boldsymbol{C}, \mathbf{D}, J-M, 100 \mu \mathrm{m}$

the contralateral tectum of astray, gaps in the innervation were observed (13 of 15 animals), presumably resulting from ectopic ipsilateral innervation by the unlabeled eye. Ipsilateral tectum innervation is probably a consequence of axons recrossing the midline caudal to the chiasm, because ipsilateral growth of axons at the chiasm was rare and indistinguishable from wild type (data not shown) (Becker et al., 2000).

Discrete blocks of tectal innervation probably represent eyespecific segregation of optic axons into ocular dominance columns. Ocular dominance columns are induced in the tectum of frogs (Constantine-Paton and Law, 1978) and fish (Meyer, 1982) in an activity-dependent manner, whenever more than one eye innervates one tectal half. Moreover, tracing the larval optic projection from the left and right eyes with two different lipophilic tracers in astray mutants often labels segregated patches of innervation on the tectum, directly showing the presence of ocular dominance columns in larval astrays (C.-B.C., data not shown). This suggests that robo2 is not required for activity-dependent axon/axon interactions.

Aberrant growth of optic axons into the tectum

The dorsal brachium of the optic tract is tightly fasciculated in wild-type animals $(n=12$; Fig. $2 J)$. In all adult astray mutants, it enters the tectum in an abnormally broad front of individual fascicles ( 15 of 15 animals; Fig. $2 \mathrm{~K}$ ), indicating defasciculation of the optic tract in astray mutants. Within the tectum, close to the dorsal midline, fascicles of optic axons run deep, giving off axons dorsally to terminate in the superficial retinorecipient layers (13 of 15 animals; Fig. 2D). This never occurs in wild type (Fig. 2C). Optic axon fascicles deep within the tectum are most likely a consequence of defasciculated growth into the tectum, since individual fascicles can be seen to enter the rostral tectum ventral to the retinorecipient zone (Fig. $2 K$ ).

\section{Expanded target innervation}

Larval astray mutants exhibit larger terminal arbors than wildtype animals (Campbell et al., 2007). In adult wild-type animals, terminal fields are small, dense and sharply delineated. In the adult astray mutants retinorecipient pretectal nuclei, including the central pretectal nucleus (CPN), anterior thalamus (A), ventrolateral thalamus (VL) and the dorsal part of the periventricular pretectal nucleus (PPd), showed expanded innervation fields with more diffuse borders (15 of 15) compared with wild type (Fig. 2E,F). We were able to quantify the lateral extent of the A/VL terminal field at the level of the CPN, which was significantly enlarged in astray mutants (203.2 $\pm 18.4 \mu \mathrm{m} \mathrm{SEM})$ com- 
pared with wild-type animals $(124.7 \pm 6.7 \mu \mathrm{m}$; Mann-Whitney $U$ test, $p=0.0005)$. However, the cytoarchitecture of the pretectal area, visualized by Neutral Red counterstain, was indistinguishable in wild-type and astray animals. For example the distance between the CPN and the dorsal aspect of the ventricle was comparable between astray $(333.5 \pm 13.4 \mu \mathrm{m})$ and wild-type animals $(323.3 \pm 14.1 ; p=0.6)$. This suggests that optic axons terminated beyond their normal boundaries.

In the tectum of wild-type animals, most optic axons terminate in the stratum fibrosum et griseum superficiale (SFGS). In contrast, in astray mutants terminations of axons were more dispersed. A substantial proportion of optic axons innervated layers that were deeper than the SFGS (15 of 15 animals; Fig. 2G,H), resulting in a doubling in the depth of densely innervated tectal layers. The total depth of the termination zone in astray mutants was $92.4 \pm 3.7 \mu \mathrm{m}$ compared with $48.8 \pm 1.7 \mu \mathrm{m}$ in wild-type animals (ANOVA, $p<0.0001$ ), whereas the total thickness of the tectum was unchanged in astray mutants $(185.1 \pm 4.3 \mu \mathrm{m})$, compared with wild-type animals (198.3 $\pm 10.2 \mu \mathrm{m}$, Mann-Whitney $U$ test, $p=0.4)$. This suggests that optic axons terminated beyond their normal target layers. Overall, developmental pathfinding and termination errors of optic axons in astray mutants are mostly retained in adults. Thus long-term error correction of the optic projection is inefficient in astray mutants.

\section{Robo2 deficiency is not the reason for inefficient correction of pathfinding errors of optic axons}

Is the failure to correct pathfinding errors a consequence of the lack of Robo2? It is possible that robo2 function is not only needed for correct pathfinding and terminal branching of optic axons, but also for error correction once ectopic tracts are present. Alternatively, a lack of error correction could be a general property of optic axons in zebrafish. To distinguish between these alternatives, we conditionally knocked down robo2 expression during early development to induce targeting errors, but allowed robo2 expression levels to recover during subsequent development, so as not to interfere with a possible robo2-dependent correction mechanism.

To this end, we injected a splice-blocking morpholino against robo2 into embryos. Our PCR analysis of mRNA extracts from injected larvae indicated a reduction in correctly spliced robo2 mRNA at 3 days postfertilization (dpf) (Fig. 1C). At this time point the optic projection first forms a retinotopic projection on the tectum (Kaethner and Stuermer, 1994). However, significant amounts of correctly spliced mRNA were still detectable, indicating only a partial knockdown. Importantly, a shorter aberrant band was detected by RT-PCR. We cloned and sequenced this band and found that it lacked a large part of exon 1, including 57 bp of coding sequence (spanning the start codon) and $24 \mathrm{bp}$ of the 5' UTR, indicating usage of a cryptic upstream splice donor. While the predicted first ATG in the aberrantly spliced RNA is in frame, it lies 197 bp downstream of the usual start codon, well past the signal sequence and halfway through the first Ig domain of Robo2. It is thus very likely that no functional protein is translated from this RNA. As expected, at $5 \mathrm{dpf}$ levels of correctly spliced robo 2 mRNA were close to normal and expression of the aberrantly spliced mRNA was reduced. The aberrant band was nearly undetectable by $18 \mathrm{dpf}$. Thus, the morpholino partially knocks down robo 2 expression and becomes ineffective by $18 \mathrm{~d}$ postfertilization.

Analysis of the optic projection at $5 \mathrm{dpf}$ by DiI tracing in wild-type larvae and live observation of GFP fluorescence in pou4f3:GFP transgenic larvae after morpholino injection showed a partial phenocopy of the astray mutant. Of 12 DiI traced larvae, 2 showed aberrant growth of the optic projection, with ectopic projections to the telencephalon, although these projections appeared unilateral-unlike most astray mutants-perhaps reflecting an incomplete knockdown of robo2 function (Fig. 1D,E). A few of the ectopic axons appeared to recross the midline in the posterior commissure, but no other astray-like errors were observed. The telencephalic pathfinding errors seen in robo2 morphants (morpholino-injected animals) are a definitive phenotype, very specifically associated with astray mutants and never observed in thousands of wild-type larvae or after injecting scores of other morpholinos (C.-B.C., unpublished data). Combined with the RT-PCR data, this partial phenocopy of the astray phenotype therefore indicates a specific action of the morpholino (Nasevicius and Ekker, 2000).

To determine whether ectopic tracts in the telencephalon are retained in adulthood, we sorted live pou4f3:GFP transgenic robo 2 morphants and raised those that had these tracts. The frequency of ectopic telencephalic tracts was $16.4 \pm 4.4 \%(n=243$ larvae), which was lower than in astray mutants (67\%), likely because of incomplete knockdown of robo2 (Fig. $1 A, D, E$ ). In adult robo2 morphants that had been presorted as larvae for an ectopic telencephalic projection, tracing from both optic nerves showed a retained ectopic projection $(n=5)$. Ectopic tracts were not as massive as those observed in astray mutants, probably because transient morpholino efficacy allowed later-developing optic axons to pathfind correctly.

Of 4 additional unilaterally traced animals, 1 showed axons in the telencephalon (Fig. $1 H$ ). In addition, two of the unilaterally traced animals showed ectopic tracts in the telencephalon that were not labeled by the tracer, but clearly discernable because of their whitish-appearing myelin and asymmetrical location in dissected brains (data not shown). It is likely that these aberrant tracts consist of optic axons derived from the unlabeled eye, which would suggest that aberrant tracts in morpholino-injected animals often derive from only one eye. This would also be consistent with the unilateral telencephalic projection in morpholino-injected larvae (see above).

In addition to telencephalic projections, we observed ocular dominance column-like innervation of the ipsilateral tectum in 1 of 4 unilaterally traced animals, indicating that ectopic midline crossing occurred in morpholino-injected animals. Other errors of optic axons observed in astray mutants, such as caudal growth into the tegmentum, more dispersed terminations, and irregular growth into the tectum were not found in adult morpholinoinjected animals. Specifically, the terminations of optic axons were not more dispersed in morpholino-treated fish $(n=9$ animals; mean thickness of tectal termination zone: $47.8 \pm 1.41 \mu \mathrm{m}$, ANOVA, $p=0.8$ ) than in uninjected wild-type animals (48.8 \pm 1.7; Fig. 2I). This is consistent with the absence of these late phenotypes in morphant larvae.

Thus ectopic growth of optic axons, caused by partial knock down of robo 2 expression during early development, is not corrected during subsequent development when robo2 expression levels have recovered. Overall, this suggests the general absence of an efficient correction mechanism for developmental pathfinding errors of optic axons in zebrafish.

\section{Degenerating tracts are not a strong guidance cue for regenerating optic axons}

Next we asked whether degenerating optic tracts are a nonspecific guidance cue for regenerating optic axons. If this was the case, regenerating optic axons in astray should faithfully repopulate 

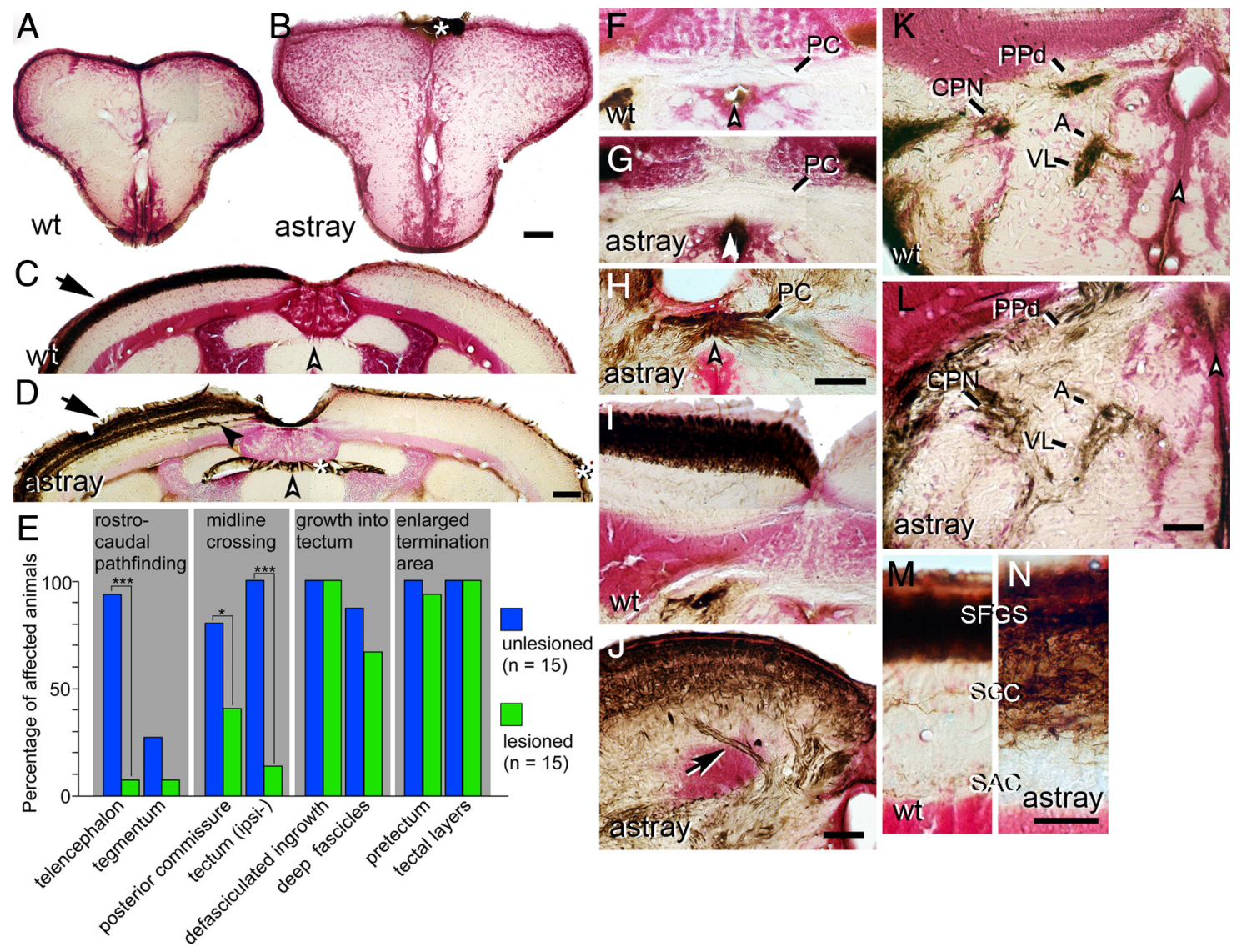

Figure 3. Correction and recurrence of errors by regenerating optic axons in adult astray mutants. Optic axons are stained brown in cross sections of the adult brain (counterstained in red); dorsal is up. White arrowheads indicate the brain midline. Asterisks indicate nonspecific labeling of the meninges. $\boldsymbol{A}, \boldsymbol{B}$, No regenerated optic axons are present in wild-type $(\boldsymbol{A})$ or astray $(\boldsymbol{B})$ telencephalon. $\boldsymbol{C}, \boldsymbol{D}$, The regenerated optic projection in the tectum is exclusively contralateral (arrow) in wild type $(\boldsymbol{C})$ and astray $(\boldsymbol{D})$, but erroneous growth of deep fascicles (black arrowhead in $\boldsymbol{D})$ recurs in astray. $\boldsymbol{E}$, Frequencies of different astray phenotypes before and after regeneration of the optic projection in animals preselected for the presence of telencephalic tracts in larvae. ${ }^{*} p<0.05$, ${ }^{* * *} p<0.0001$. $\boldsymbol{F}-\boldsymbol{H}$, Regenerating optic axons do not cross the posterior commissure (PC) in wild-type fish $(\boldsymbol{F})$. Regenerated optic axons show ectopic crossing in the posterior commissure in some astray animals $(\boldsymbol{H})$, but not in others $(\boldsymbol{G}) . \boldsymbol{I}, \boldsymbol{J}$, Regenerated axons enter the tectum in separate fascicles in astray (arrow in $\boldsymbol{J})$, but not in wild type $(\boldsymbol{I}) . \boldsymbol{K}, \boldsymbol{L}$, Termination areas of regenerated optic axons in the pretectum are expanded in astray animals $(\boldsymbol{L})$, compared with wild-type animals $(\boldsymbol{K}) . \boldsymbol{M}, \boldsymbol{N}, \operatorname{In}$ astray $(\boldsymbol{N})$, reinnervation of tectal layers is expanded compared with wild type $(\boldsymbol{M})$ after regeneration. For abbreviations see Figure 2. Scale bars: $A, B, 200 \mu \mathrm{m} ; \boldsymbol{C}, \boldsymbol{D}, \boldsymbol{F}-\mathbf{L}, 100 \mu \mathrm{m} ; \boldsymbol{M}, \boldsymbol{N}, 50 \mu \mathrm{m}$.

not only the entopic tracts found in wild-type animals but also ectopic tracts, such that the regenerated projection looks similar to the unlesioned projection in astray. Alternatively, if regenerating axons can only use specific pathfinding cues, they should rarely follow ectopic tracts, which lack such cues. To distinguish between these scenarios, we determined whether regenerating optic axons projected to the telencephalon in astray mutants.

A regenerated optic projection in adult zebrafish is indistinguishable from an unlesioned projection, except for a slight increase in the occurrence of ipsilateral optic axons in the optic tract (Becker et al., 2000). Adult astray mutants with a confirmed larval optic projection to the telencephalon received an optic nerve lesion and the regenerated projection was traced unilaterally at 4 weeks postlesion. Rostrocaudal pathfinding errors were strongly reduced in the regenerated projection: Ectopic tracts in the telencephalon were observed in none of the wild-type fish with a regenerated optic projection (Fig. 3A) and in only 1 of 15 astray animals (Fig. $3 B$ ). This is significantly different from unlesioned astray animals ( 14 of 15, see above; Fisher's exact test, $p<$ $0.0001)$. In the tegmentum, optic axons were present in no wildtype animals and in only 1 of 15 astray mutants with a regenerated optic projection, compared with 4 of 15 unlesioned astray animals, showing the same tendency to correct developmental pathfinding errors during regeneration.

\section{Cellular and molecular changes after deafferentation are} similar in ectopic and entopic optic tracts

Regeneration of optic axons into ectopic tracts could have been prevented by a degeneration that was too quick, such that the tracts had disappeared by the time axons arrived in the brain, or delayed, such that entry was blocked for regenerating axons. Ectopic tracts could also differ from entopic tracts in the expression of growth promoting molecules they contain. Therefore, we decided to observe degeneration of ectopic and entopic tracts and gene expression at a time point when entopic tracts are about to be repopulated.

To determine when axons regenerate we performed anterograde tracing experiments of the optic projection. At $8 \mathrm{~d}$ after an optic nerve cut lesion, 11 of 13 wild-type animals had regenerating axons in the diencephalic optic tract and in 8 of 13 animals axons had reached the rostral tectum. By $16 \mathrm{~d}$ postlesion, all animals $(n=4)$ had optic axons reaching the caudal tectum and 3 of 4 animals exhibited complete coverage of the tectum by optic axons (data not shown). This indicates that at $\sim 1$ week postlesion, axons have regrown to an extent that they could have entered ectopic telencephalic tracts.

As an indicator of tract degeneration, we decided to observe macrophage/microglial cell invasion of ectopic telencephalic tracts at 1 week postlesion by immunohistochemistry. Tracts 
were identified by their dark appearance in differential interference contrast microscopy, their typical asymmetrical dorsoventral extent, and dense immunolabeling for macrophages/microglial cells. We found a massive macrophage/ microglial cell reaction that was comparable between ectopic and entopic tracts in all astray mutants ( $n=4$ animals; Fig. 4 ). The macrophage/microglial cell reaction in astray was not different from lesioned wild-type animals $(n=4)$ (Schweitzer et al., 2003, 2007). This suggests a similar timing of degeneration in ectopic and entopic tracts in astray animals.

To determine whether oligodendrocytes might have failed to increase expression of axon growth-promoting molecules (Becker and Becker, 2007) in ectopic tracts of astray animals, we double-labeled sections for contactin1a mRNA by in situ hybridization. Contactinla mRNA is upregulated by oligodendrocytes of the optic tract after a lesion and may promote axon growth (Schweitzer et al., 2007). We found a similar increase in expression of contactin1a mRNA in ectopic and entopic tracts in astray animals at $7 \mathrm{~d}$ postlesion. This matched increased expression observed in lesioned wild-type animals $(n=4$; data not shown) (Schweitzer et al., 2007). This suggests that ectopic tracts contain oligodendrocytes that display a typical lesion response. Thus, at least some aspects of the cellular and molecular composition of ectopic and entopic tracts are comparable at a time when regenerating axons choose their path.

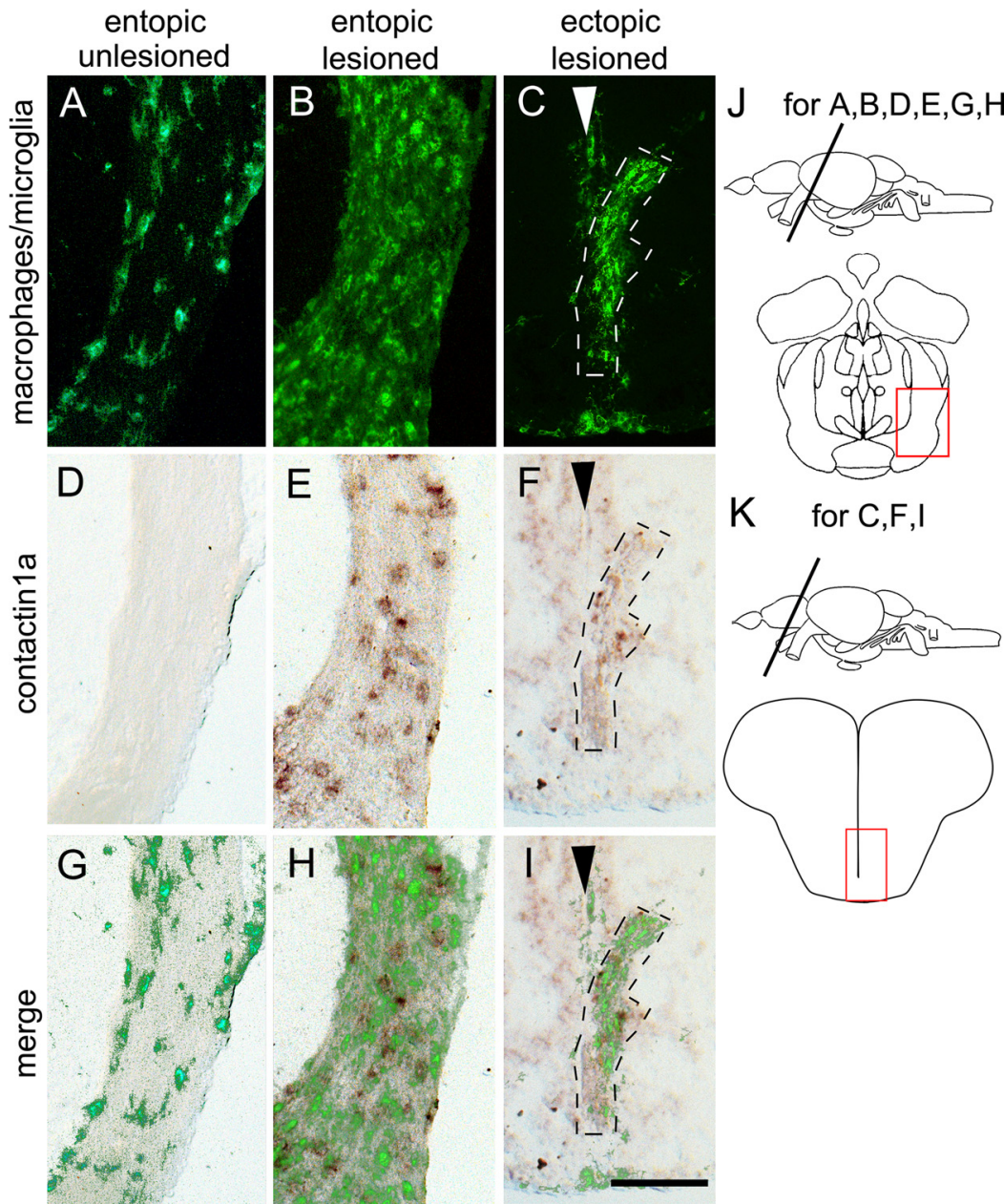

Figure 4. Deafferented ectopic optic tracts in the telencephalon of astray mutants display macrophage/microglial cell activation and increased contactin 1a mRNA expression comparable to entopic tracts. Cross sections through the adult brain are shown as indicated in $\boldsymbol{J}$ and $\boldsymbol{K}$. Macrophage/microglial cell immunolabeling $(\boldsymbol{A}-\boldsymbol{C})$ and contactin1a mRNA labeling $(\boldsymbol{D}-\boldsymbol{F})$ is comparable between deafferented entopic $(\boldsymbol{B}, \boldsymbol{E}, \boldsymbol{H})$ and ectopic astray optic tracts $(\boldsymbol{C}, \boldsymbol{F}, \boldsymbol{I})$. Both signals are increased compared with unlesioned entopic tracts $(\boldsymbol{A}, \boldsymbol{D}, \boldsymbol{G})$. Arrowheads in $\boldsymbol{C}, \boldsymbol{F}$, and $\boldsymbol{I}$ indicate telencephalic midline. $\mathbf{G}-\boldsymbol{I}$ show superimposition of macrophage/microglial cell and contactin $1 a$ mRNA labeling. Scale bar, $200 \mu \mathrm{m}$.

\section{Pathfinding errors but not termination errors of optic axons are reduced in the regenerated optic projection of astray mutants}

To test the hypothesis that robo2 deficiency impairs correct regeneration of optic axons, we analyzed the entire trajectories of regenerated optic axons in astray mutants. In the following we describe errors committed by regenerating optic axons in astray mutants, which were never observed in wild-type animals, unless stated otherwise (13 animals). Error frequencies are compared with those in unlesioned astray mutants (Fig. $3 E$ ).

Robo 2 deficiency does not influence the frequency of erroneous ipsilateral axon growth in the chiasm during optic nerve regeneration. Even though ipsilateral axons were observed in regenerated astray mutants ( 8 of 15 animals) at a higher frequency than in unlesioned astray mutants ( 1 of 15 , Fisher's exact test, $p=$ $0.014)$, this proportion still matched that of regenerated wildtype animals ( 6 of 13, not significant, data not shown). This confirms our earlier observation that regenerating optic axons show an elevated rate of ipsilateral growth during regeneration even in wild-type animals (Becker et al., 2000).

In the posterior commissure, ectopic midline crossing was reduced compared with unlesioned astray mutants. Optic axons crossing in the posterior commissure were present in the regenerated projection in only 6 of 15 animals, compared with 12 of 15 in unlesioned astray animals (one-sided Fisher's exact test, $p=0.03$; Fig. $3 F-H)$.

In the tectum ipsilateral innervation was also strongly reduced. Two of 15 astray animals with a regenerated optic projection showed ipsilateral tectal innervation, which was significantly less than in unlesioned astray mutants (15 of 15; Fisher's exact test, $p<0.00001$; Fig. 3C,D). Reduced ipsilateral innervation is probably a consequence of reduced midline crossing in the posterior commissure.

Defasciculation of the dorsal optic tract as it enters the tectum ( 15 of 15 animals; Fig. $3 I, J$ ) and ectopic fascicles of optic axons in deep tectal layers (10 of 15 animals; Fig. 3C,D) were observed in astray mutants with a regenerated optic projection. This was not statistically different from frequencies of phenotypes found in unlesioned astray mutants (15 of 15 animals for defasciculation of the dorsal optic tract and 13 of 15 animals for the presence of ectopic fascicles in deep tectal layers; Fig. $3 E$ ).

Termination patterns of regenerating astray axons were indistinguishable from unlesioned astray mutants. Reinnervated terminal fields in pretectal nuclei were expanded in 14 of 15 animals, whereas the regenerated innervation of pretectal nuclei was 


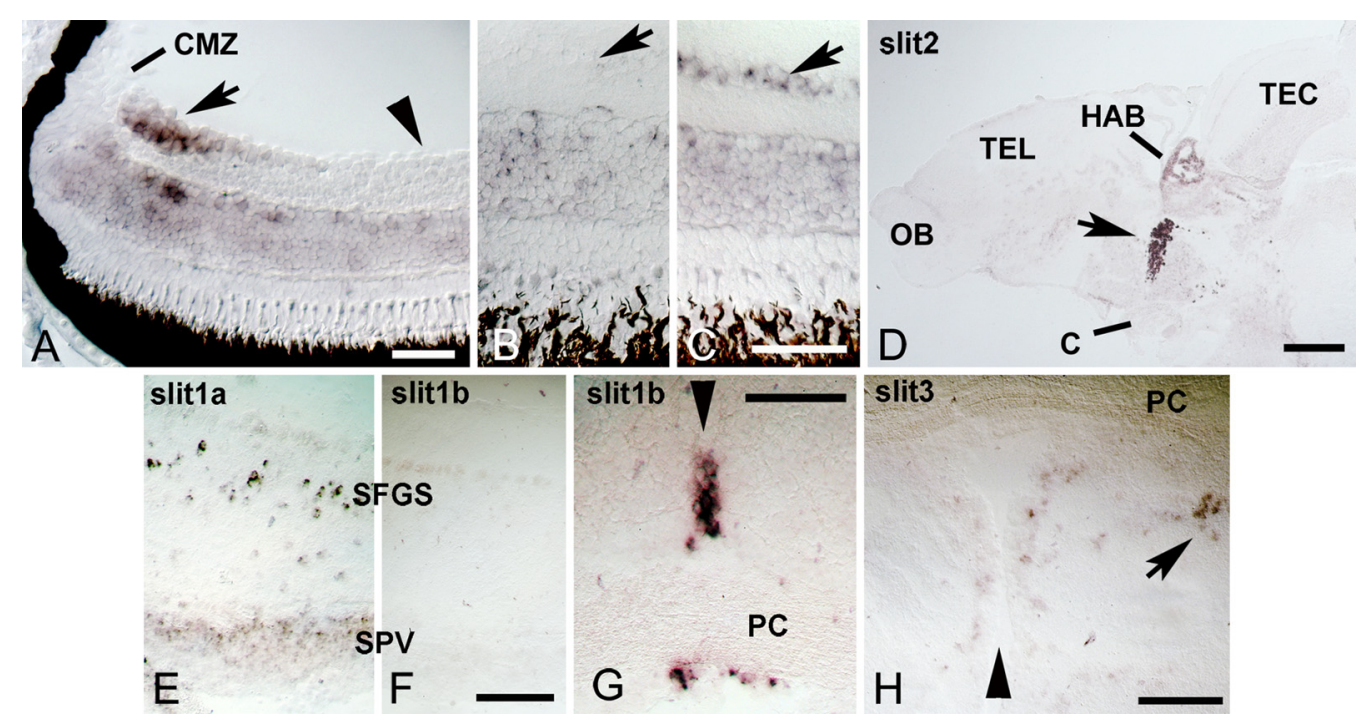

Figure 5. Robo2 and slits are expressed during regeneration of the adult optic projection. Cross sections are shown, except for $\mathbf{D}$. $\boldsymbol{A}$, In the retina of unlesioned juvenile, 4-week-old animals, robo2 mRNA is expressed in recently differentiated retinal ganglion cells in the peripheral growth zone of the retina (arrow) next to the ciliary margin zone (CMZ). Older, more central retinal ganglion cells (arrowhead) do not express detectable levels of robo2 mRNA. $B, C$, In the adult ( $>3$ months of age) central retina, robo2 mRNA is reexpressed in the retinal ganglion cell layer at 2 weeks postlesion (arrow in C) compared with the retinal ganglion cell layer in unlesioned controls (arrow in B). D, A sagittal section of the brain is shown (rostral left, dorsal up). Conspicuous expression of slit2 mRNA is found in the habenula (HAB) and in the ventral diencephalon (arrow) at the level of the optic chiasm (C). OB, Olfactory bulb; TEL, telencephalon; TEC, tectum mesencephali. $E$, $F$, Slit1 a (E), but not slit $1 b(\boldsymbol{F})$, is expressed in the deafferented tectum at 1 week postlesion. SPV, stratum periventriculare; SFGS, stratum fibrosum et griseum superficiale. G, Strong local expression of slit $1 b$ mRNA is found at the level of the posterior commissure (PC) in cross sections of the brain. $\boldsymbol{H}$, Low levels of slit3 $\mathrm{mRNA}$ expression are found in the pretectum, including the PPd area (arrow). Arrowheads in $\boldsymbol{G}$ and $\boldsymbol{H}$ indicate the brain midline. Scale bars: $\boldsymbol{A}, 50 \mu \mathrm{m} ; \boldsymbol{B}, \mathbf{C}, 50 \mu \mathrm{m} ; \boldsymbol{D}, 200 \mu \mathrm{m} ; \boldsymbol{E}, \boldsymbol{F}, 100 \mu \mathrm{m} ; \boldsymbol{G}, 50 \mu \mathrm{m} ; \boldsymbol{H}, 100 \mu \mathrm{m}$.

highly precise in all wild-type fish $(n=13$ animals; Fig. $3 K, L)$. Tectal innervation was also expanded in all astray mutants with a regenerated projection (mean depth of termination zone: $89.6 \pm$ $2.6 \mu \mathrm{m})$ matching that of unlesioned astray mutants (92.4 \pm 3.7 $\mu \mathrm{m}$, see above) and significantly thicker than in wild-type animals with a regenerated optic projection (depth of termination zone: $48.5 \pm 1.9 \mu \mathrm{m}$; ANOVA, $p<0.0001$; Fig. $3 M$ ).

Thus, many pathfinding errors of optic axons occur much less frequently (rostrocaudal errors, ectopic midline crossing) in astray fish with a regenerated optic projection than in unlesioned mutants. However, irregular growth into the tectum and termination errors in the pretectum and tectum are repeated. The simplest explanation for these repeated errors is that robo 2 is required for certain pathfinding decisions and for correct termination of regenerating axons.

robo 2 and slits are expressed during optic nerve regeneration Next we asked whether robo2 and slit ligands are expressed at the right time and place to be involved in targeting of regenerating optic axons in adult fish. We performed in situ hybridization for robo2 in the retina, as well as the potential ligands slit1a, slit1b, slit2 and slit3 in the optic pathway and in the brain, before and after optic nerve crush of wild-type animals. The retina of adult teleost fish grows continuously in an annular fashion, i.e., central retina is older than peripheral retina (Easter and Stuermer, 1984). In the juvenile zebrafish retina (4 weeks postfertilization), robo2 is expressed in the peripheral growth zone of the retina, next to the undifferentiated ciliary margin zone (Fig. 5A). In more central, older parts of the retina the retinal ganglion cells did not show detectable levels of robo2 mRNA expression. This is typical for genes involved in axonal growth of newly formed retinal ganglion cells (Bernhardt et al., 1996; Laessing and Stuermer, 1996).

In the unlesioned adult retina (Fig. 5B), no robo2 mRNA expression was detected in the retinal ganglion cell layer. At 1 week after a lesion of the optic nerve in adult animals, when most axons have passed the chiasm/optic tract region, robo2 mRNA expression was not detectably upregulated in the retina by in situ hybridization and PCR (data not shown). However at 2 weeks postlesion, when axons navigate close to their targets, upregulation in the retinal ganglion cell layer of the entire retina was detectable by in situ hybridization (Fig. 5C).

Slits showed mRNA expression in the brain that was unchanged between unlesioned animals and animals at 2 weeks postlesion and is described here as it pertains to the optic projection. Slit1 a mRNA showed the most widespread expression in the brain, including the ventral diencephalon and the tectum. In the tectum, expression was strongest in large neurons in the SFGS. The mRNA was also detectable in the outer aspect of the cell dense stratum periventriculare (SPV), but not in the ventricular layer of ependymo-radial glial cells (Fig. 5E). Slit1b mRNA expression was mostly restricted to specific brain midline zones, such as at the medial aspect of the habenula and at the level of the posterior commissure (Fig. $5 F, G$ ). Low levels of expression were detected in the ventral telencephalon, rostral to the chiasm. Slit2 showed strong and highly localized mRNA expression throughout the habenula and in the ventral diencephalon at the level of the chiasm (Fig. 5D). Slit3 mRNA showed low levels of expression in the $\mathrm{A} / \mathrm{VL}$ and PPd region of the diencephalon (Fig. $5 H$ ). A strong slit3 mRNA signal was found in the tegmental midline, which did not coincide with the trajectories of optic axons (data not shown). Thus, retinal ganglion cells with regenerating axons express robo 2 mRNA, while their axons navigate a brain that expresses slit ligands close to the optic pathway.

\section{Tectal cytoarchitecture is comparable between astray and wild-type animals}

Expansion of optic axon terminations beyond wild-type retinorecipient layers is consistently found in all astray mutants with a regenerated optic projection. To estimate the potential contribution of developmentally altered brain morphology to these 


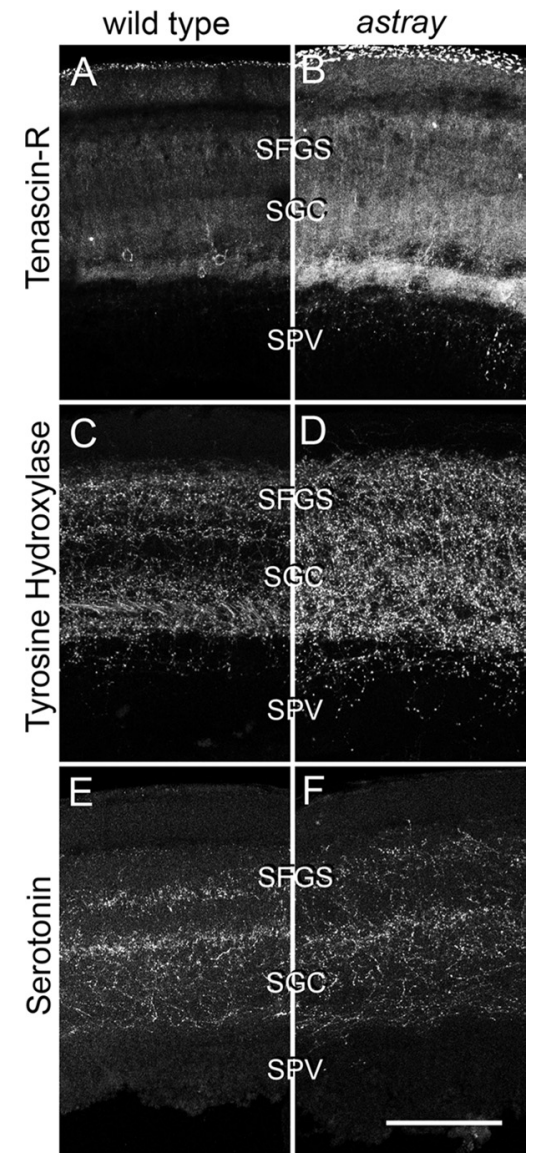

Figure 6. Comparison of laminar distribution of different markers in the denervated tectum at 1 week postlesion. Cross sections through the dorsal tectum are shown (dorsal is up). Tenascin- $R(\boldsymbol{A}, \boldsymbol{B})$, tyrosine hydroxylase $(\boldsymbol{C}, \boldsymbol{D})$, and serotonin $(\boldsymbol{E}, \boldsymbol{F})$ immunoreactivities show comparable distribution in wild-type and astray animals. However, labeling intensity of Tenascin- $R$ and tyrosine hydroxylase was increased in astray mutants relative to wild-type animals. For anatomical abbreviations see previous figures. Scale bar, $100 \mu \mathrm{m}$.

targeting errors, we analyzed the laminated architecture of the denervated tectum. We found that the layered expression of Tenascin-R (Becker et al., 2004), another extracellular matrix protein, as well as tyrosine hydroxylase and serotonin immunopositive afferents (Kaslin and Panula, 2001) was comparable between astray mutants and wild-type animals in the tectum at 1 week postlesion (Fig. 6). At this time, the tectum is denervated and the first regenerating optic axons have just begun to reach it (see above). However, the intensity of Tenascin-R immunoreactivity increased by $41 \%(n=3$ animals, mean pixel brightness was $96.2 \pm 6.7$ in astray and $68.0 \pm 5.5$ in wild type, Mann-Whitney $U$ test, $p<0.05)$. Intensity of tyrosine hydroxylase-immunopositive axons increased by $94 \%(n=3$, brightness was $48.0 \pm 3.1$ in astray and $24.8 \pm 2.0$ in wild type, Mann-Whitney $U$ test, $p<$ 0.05 ). Serotonergic innervation was unchanged (brightness was $37.4 \pm 12.0$ in astray and $37.0 \pm 12.0$ in wild type). As the basic layering of extracellular matrix and afferent systems is retained in astray mutants, it is unlikely that the massive laminar termination errors of regenerating optic axons are solely caused by developmentally altered tectal cytoarchitecture.

\section{Ubiquitous overexpression of Slit2-GFP during regeneration of the optic projection does not lead to major pathfinding errors}

To determine the effect of acutely compromising Robo/Slit signaling during regeneration we ubiquitously overexpressed a robo ligand to mask endogenous slit expression patterns. We used a fish line ( $h s p 70 l: s l i t 2-G F P)$ in which Slit2-GFP fusion protein overexpression can be induced by heat shock (Yeo et al., 2004). In all heat-shocked embryos, the optic tract is severely disrupted after a single heat-shock, including astray-like rostral and caudal pathfinding errors; such profound disruption is never seen in hsp70l:mcherry controls (Fig. 7A,B). Daily heat-shocks of adults led to a homogeneous $82 \%$ increase in immunodetectability of GFP in sections of the adult brain (non-heat shock: $9.8 \pm 2.30$, $n=6$ animals; heat shock: $17.9 \pm 2.70, n=8$ animals; $p=0.01$ ), indicating successful overexpression of Slit2 (Fig. 7C-F). Applying this treatment to animals with optic nerve lesions did not lead to ectopic telencephalic (Fig. $7 G, H$ ) or tegmental projections, nor crossing of axons in the posterior commissure (Fig. $7 \mathrm{~K}, L$ ), presence of ipsilateral axons in the tectum or increased termination layer depth of optic axons during regeneration $(n=4$ animals). We detected deep running fascicles of optic axons in the rostromedial tectum of all animals $(n=4)$, not found in wild type. However, this was also observed in all unlesioned hsp70l: slit2-GFP fish $(n=12)$, which possessed an otherwise wild-typelike optic projection. Thus, ubiquitous overexpression of slit2 during optic nerve regeneration did not induce astray-like pathfinding phenotypes. This is consistent with a reduced importance of Robo/Slit interactions for pathfinding of adult regenerating optic axons.

\section{Discussion}

We show here for the first time that degenerating tracts are not a strong guidance cue for regenerating CNS axons, that robo2 may contribute to correct pathfinding and termination of regenerating optic axons, and that correction of large-scale developmental pathfinding errors of optic axons is inefficient in zebrafish.

\section{Degenerating tracts in the CNS are not an attractive guidance cue}

The adult astray mutant uniquely enabled us to test whether degenerating CNS tracts are a strong guidance cue for regenerating axons. This is because the mutant contains ectopic optic tracts that develop stochastically in two thirds of the animals and are mostly retained in adults. Thus, regenerating axons are confronted with degenerating tracts that do not overlap with the correct trajectory to their targets.

If degenerating tracts were an attractive guidance cue, we would expect regenerating optic axons to reenter these tracts in almost all cases. However, growth of regenerating optic axons into the telencephalon was extremely rare ( 1 of 15 animals) following an optic nerve crush in astray mutants that had been preselected for the presence of a telencephalic projection at the larval stage. Ectopic tracts were clearly present at 1 week postlesion and underwent degeneration that was indistinguishable from entopic and wild-type tracts, as judged by the macrophage/ microglial cell response. This was the time point when regenerating optic axons repopulated tracts in the brain. Moreover, evidence from previous enucleation experiments (Schweitzer et al., 2003, 2007) indicates that optic tracts are unchanged in diameter through at least 4 weeks postlesion, when regeneration is complete (Becker et al., 2000). This strongly suggests that degenerating ectopic tracts are available to regenerating axons, but are not reentered. This differs from observations in the peripheral nervous system in mice, where repeated imaging of regenerating motor axons suggested that they retraced their former trajectories within remaining Schwann cell tubes because of mechanical constraints and possibly by interacting with Schwann cell and 

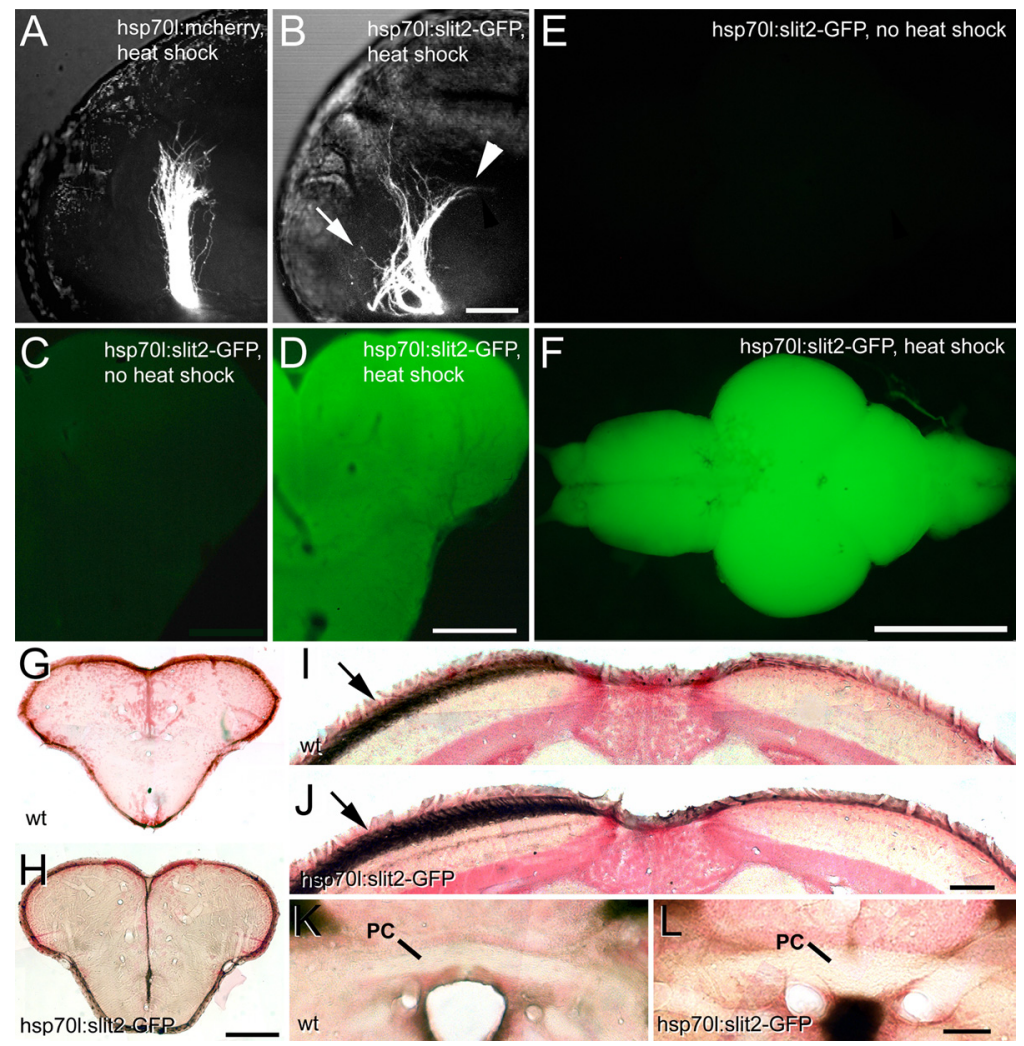

Figure 7. Ubiquitous overexpression of Slit2-GFP causes astray-like phenotypes in the developing, but not the regenerating optic projection. $\boldsymbol{A}, \boldsymbol{B}$, Lateral views (maximal-intensity projections) of optic axons in heat-shocked embryos at $48 \mathrm{hpf}$ show an essentially wild-type projection in hsp70l:mcherry control embryos, but in hsp70l:slit2-GFP embryos the tract is severely disorganized with anterior (arrow) and posterior (arrowhead) misprojections. $\mathbf{C}-\boldsymbol{F}$, After repeated heat-shocks the entire brain of hsp70l: slit2-GFP animals $(\boldsymbol{F})$ shows intense GFP fluorescence, compared with non-heat-shocked controls $(\boldsymbol{E})$. Similarly, immunodetection of GFP in sections of the telencephalon shows homogeneous immunoreactivity after heat shock (D), but not in non-heat-shocked controls (C). G-L, Regenerating optic axons in heat-shocked wild-type (wt) and hsp701:slit2-GFP transgenic fish do not grow into the telencephalon $(\boldsymbol{G}, \boldsymbol{H})$ or the posterior commissure ( $\mathrm{PC}$ in $\boldsymbol{K}, \boldsymbol{L})$ and exclusively populate the contralateral tectum (arrows in $\boldsymbol{I}, \boldsymbol{J}$ ). Scale bars: $\boldsymbol{A}, \boldsymbol{B}, 50 \mu \mathrm{m} ; \boldsymbol{C}, \boldsymbol{D}, 200 \mu \mathrm{m} ; \boldsymbol{E}, \boldsymbol{F}, 1 \mathrm{~mm} ; \boldsymbol{G}, \boldsymbol{H}, 200 \mu \mathrm{m} ; \boldsymbol{I}, \boldsymbol{J}, 100 \mu \mathrm{m} ; \boldsymbol{K}, \boldsymbol{L}, 50 \mu \mathrm{m}$.

basal lamina derived growth-promoting molecules (Nguyen et al., 2002). Similarly, it has been suggested from electronmicroscopic observations of the optic nerve of salamanders that regenerating optic axons use degenerating fibers as guidance cues (Turner and Singer, 1974).

Regenerating optic axons do not enter ectopic tracts despite the presence of growth-promoting molecules. We show here that the axon growth-promoting contactin $1 a$ is upregulated by oligodendrocytes in the lesioned ectopic tracts in a fashion similar to lesioned entopic optic tracts. This suggests that ectopic tracts are not avoided because they may lack growth promoting molecules expressed in lesioned entopic tracts. In fact, fish oligodendrocytes reexpress a number of growth promoting molecules after an optic nerve lesion, such as L1-related proteins (Bernhardt et al., 1996; Ankerhold et al., 1998) and P0 (Brösamle and Halpern, 2002; Schweitzer et al., 2003). In mammals, oligodendrocytes survive an optic nerve lesion (Ludwin, 1990), but expression of L1 and P0 is restricted to peripheral Schwann cells (Martini, 1994). Overall, this suggests that regenerating optic axons show active, target-oriented navigation during regeneration.

\section{Robo2 may contribute to correct distal targeting of regenerating optic axons}

The frequencies of specific errors committed by regenerating robo2-deficient axons (Fig. $3 E$ ) suggest that robo2 is less impor- tant for correct rostrocaudal pathfinding and avoidance of ectopic midline crossing than during development, but may be necessary for fasciculated growth of regenerating optic axons into the tectum and for precise target zone termination of optic axons.

Spatiotemporal expression patterns of robo 2 and slit ligands correlate with these differences: Robo2 is not detectably reexpressed in any retinal ganglion cells after optic nerve crush at 1 week postlesion, when regenerating optic axons have to make pathway choices in the chiasm/tract region. Rostrocaudal pathfinding errors originate in this region in unlesioned astray mutants. Thus, the slow upregulation of robo2 suggests that even in wildtype animals optic axons may not rely on Robo/Slit guidance during early regrowth. Use of alternate guidance systems may explain why in astray mutants, despite the strong expression domain of slit 2 in the diencephalon, few pathfinding errors are found close to the chiasm in the regenerated optic projection. In addition, specific slit expression domains seen near the developing chiasm are not detectable at the adult stage: In developing animals, slit3 mRNA borders the chiasm rostrally and caudally and slit 2 mRNA borders it rostrally, which channels developing optic axons into the chiasm and prevents them from forming ectopic tracts (Hutson and Chien, 2002). Moreover, we found here that conditional overexpression of slit2 during regeneration did not induce ectopic regrowth of optic axons, which is consistent with a reduced importance of Robo/Slit signaling. However, we cannot exclude that significantly increased levels of Slit2 were insufficient to fully mask endogenous slit expression domains. Together, these observations suggest that early pathway decisions of regenerating optic axons are not decisively determined by Robo/Slit interactions. Thus, other guidance cues may prevent regenerating optic axons from forming ectopic tracts during regeneration. Candidates for such cues are chondroitin sulfates (Becker and Becker, 2002), Tenascin-R (Becker et al., 2004) and Semaphorins (Becker and Becker, 2007), which are present along the adult optic pathway and may guide regenerating optic axons in a combinatorial manner.

In contrast to early pathway decisions, in more distal parts of the optic pathway, reached when robo2 reexpression is detectable in retinal ganglion cells, slit expression patterns correlate with targeting errors: The posterior commissure, through which regenerating axons aberrantly cross, is bisected by midline slit $1 b$ mRNA expression. Aberrantly large terminal fields in the pretectum correlate with slit1 $a$ and slit3 mRNA expression there. The rostral tectum, in which defasciculated growth of regenerating axons occurs and abnormal deep innervation of the tectum originates in astray mutants, is bordered by slit 2 and slit $1 b$ mRNA expression in the habenula. Expanded termination zones of optic axons in the tectum of astray mutants correlate with slit1a expression in the SFGS, the main optic axon receiving layer. In the 
developing tectum, Slit1a/Robo2 interactions negatively regulate branch tip numbers and size of terminal arbors of optic axons (Campbell et al., 2007). However, it remains to be seen whether less inhibited arbor growth in astray mutants also leads to targeting to inappropriate tectal layers of developing or regenerating optic axons.

We cannot exclude that a developmentally altered morphology of the adult astray brain may contribute to some aspects of targeting errors of regenerating astray optic axons. However, massive tectal termination errors are found in all astray animals with a regenerated optic projection, while our analysis of tectal cytoarchitecture suggests that any alterations in astray mutants are subtle. Therefore, it is likely that reexpression of robo2 in retinal ganglion cells contributes to correct distal targeting of regenerating optic axons.

\section{Correction of developmental pathfinding errors of optic axons is inefficient}

The pathfinding errors observed in the unlesioned adult projection of astray mutants are similar to those in larvae, which show rostrocaudal pathfinding errors and aberrant midline crossing (Fricke et al., 2001). Enlarged termination zones in the pretectal targets and tectum of astray adults are also reminiscent of the enlarged terminal arbors observed for single optic axons in larval astray mutants (Campbell et al., 2007). Thus, we have no evidence that developmental errors made by retinal axons in astray larvae are corrected later; in the case of pathfinding, it is clear that larval errors can persist through adulthood.

The lack of robo2 function is probably not responsible for the inability of astray mutants to correct errors, since rostral pathfinding errors caused by the temporary knock down of robo2 during early development of robo2 morphants are not corrected at later stages, when Robo2 expression has recovered.

In other axon guidance mutants, the extent of error correction for axonal pathfinding varies. In contrast to optic axons in astray, severe projection errors of peripheral nerves in Sema3A-deficient mice are corrected during development by an unknown mechanism (White and Behar, 2000). However, EphA4-deficient mice retain developmental miswiring of the corticospinal projection in adults, leading to a severely abnormal gait (Kullander et al., 2003).

In contrast to our observations in the CNS of astray, a naturally occurring transient ("erroneous") ipsilateral optic projection in amniotes appears to be eliminated by cell death because of limited trophic factor availability (Isenmann et al., 1999) and by activity-dependent pruning mechanisms involving NMDA receptors (Ernst et al., 2000). However, activity-dependent mechanisms are unlikely to be wholly defective in astray mutants, because tecta innervated by both eyes show segregation of axons into ocular dominance column-like patches, a form of axon reorganization that depends on activity (Meyer, 1982) and likely involves NMDA function (Schmidt et al., 2000) in fish.

It is possible that the misprojections in adult astray mutants have been stabilized by target-derived trophic support. This could derive from the tectum, reached in all cases by caudally misprojecting axons, or from the extensive dorsal telencephalic arborization field, reached by rostrally misprojecting axons. As the telencephalic termination field is ectopic, it is unclear which factors might stabilize optic axons that terminate here.

The functional consequences of mistargeting of optic axons in adult astray mutants are unknown. However, larval astray mutants exhibit surprisingly normal optokinetic and optomotor responses (Neuhauss et al., 1999).

\section{Conclusions}

Our findings suggest that regenerating optic axons of zebrafish show active navigation, which likely depends in part on robo2 function, and are not efficiently guided by the degenerating original tracts. This implies that presenting axons in the nonregenerating CNS of mammals with growth-promoting glial cells (Barnett and Riddell, 2007) may not be sufficient to induce directed growth of axons, unless specific navigational cues are also provided.

\section{References}

Ankerhold R, Leppert CA, Bastmeyer M, Stuermer CA (1998) E587 antigen is upregulated by goldfish oligodendrocytes after optic nerve lesion and supports retinal axon regeneration. Glia 23:257-270.

Barnett SC, Riddell JS (2007) Olfactory ensheathing cell transplantation as a strategy for spinal cord repair-what can it achieve? Nat Clin Pract Neurol 3:152-161.

Becker CG, Becker T (2002) Repellent guidance of regenerating optic axons by chondroitin sulfate glycosaminoglycans in zebrafish. J Neurosci 22:842-853.

Becker CG, Becker T (2007) Growth and pathfinding of regenerating axons in the optic projection of adult fish. J Neurosci Res 85:2793-2799.

Becker CG, Meyer RL, Becker T (2000) Gradients of ephrin-A2 and ephrinA5b mRNA during retinotopic regeneration of the optic projection in adult zebrafish. J Comp Neurol 427:469-483.

Becker CG, Schweitzer J, Feldner J, Becker T, Schachner M (2003) Tenascin- $\mathrm{R}$ as a repellent guidance molecule for developing optic axons in zebrafish. J Neurosci 23:6232-6237.

Becker CG, Schweitzer J, Feldner J, Schachner M, Becker T (2004) Tenascin- $\mathrm{R}$ as a repellent guidance molecule for newly growing and regenerating optic axons in adult zebrafish. Mol Cell Neurosci 26:376-389.

Becker T, Becker CG (2001) Regenerating descending axons preferentially reroute to the gray matter in the presence of a general macrophage/microglial reaction caudal to a spinal transection in adult zebrafish. J Comp Neurol 433:131-147.

Bernhardt RR, Tongiorgi E, Anzini P, Schachner M (1996) Increased expression of specific recognition molecules by retinal ganglion cells and by the optic pathway glia accompanies the successful regeneration of retinal axons in adult zebrafish. J Comp Neurol 376:253-264.

Brösamle C, Halpern ME (2002) Characterization of myelination in the developing zebrafish. Glia 39:47-57.

Campbell DS, Stringham SA, Timm A, Xiao T, Law MY, Baier H, Nonet ML, Chien CB (2007) Slitla inhibits retinal ganglion cell arborization and synaptogenesis via robo2-dependent and -independent pathways. Neuron 55:231-245.

Chaudhry N, Filbin MT (2007) Myelin-associated inhibitory signaling and strategies to overcome inhibition. J Cereb Blood Flow Metab 27:1096-1107.

Constantine-Paton M, Law MI (1978) Eye-specific termination bands in tecta of three-eyed frogs. Science 202:639-641.

Dickson BJ, Gilestro GF (2006) Regulation of commissural axon pathfinding by slit and its robo receptors. Annu Rev Cell Dev Biol 22:651-675.

Easter SS Jr, Stuermer CA (1984) An evaluation of the hypothesis of shifting terminals in goldfish optic tectum. J Neurosci 4:1052-1063.

Ernst AF, Gallo G, Letourneau PC, McLoon SC (2000) Stabilization of growing retinal axons by the combined signaling of nitric oxide and brain-derived neurotrophic factor. J Neurosci 20:1458-1469.

Fricke C, Lee JS, Geiger-Rudolph S, Bonhoeffer F, Chien CB (2001) Astray, a zebrafish roundabout homolog required for retinal axon guidance. Science 292:507-510.

Halloran MC, Sato-Maeda M, Warren JT, Su F, Lele Z, Krone PH, Kuwada JY, Shoji W (2000) Laser-induced gene expression in specific cells of transgenic zebrafish. Development 127:1953-1960.

Hutson LD, Chien CB (2002) Pathfinding and error correction by retinal axons: the role of astray/robo2. Neuron 33:205-217.

Hutson LD, Jurynec MJ, Yeo SY, Okamoto H, Chien CB (2003) Two divergent slit1 genes in zebrafish. Dev Dyn 228:358-369.

Isenmann S, Cellerino A, Gravel C, Bähr M (1999) Excess target-derived brain-derived neurotrophic factor preserves the transient uncrossed retinal projection to the superior colliculus. Mol Cell Neurosci 14:52-65.

Kaethner RJ, Stuermer CA (1994) Growth behavior of retinotectal axons in 
live zebrafish embryos under TTX-induced neural impulse blockade. J Neurobiol 25:781-796.

Karlstrom RO, Trowe T, Klostermann S, Baier H, Brand M, Crawford AD, Grunewald B, Haffter P, Hoffmann H, Meyer SU, Müller BK, Richter S, van Eeden FJ, Nüsslein-Volhard C, Bonhoeffer F (1996) Zebrafish mutations affecting retinotectal axon pathfinding. Development 123:427438.

Kaslin J, Panula P (2001) Comparative anatomy of the histaminergic and other aminergic systems in zebrafish (Danio rerio). J Comp Neurol 440:342-377.

Kullander K, Butt SJ, Lebret JM, Lundfald L, Restrepo CE, Rydström A, Klein R, Kiehn O (2003) Role of EphA4 and EphrinB3 in local neuronal circuits that control walking. Science 299:1889-1892.

Laessing U, Stuermer CA (1996) Spatiotemporal pattern of retinal ganglion cell differentiation revealed by the expression of neurolin in embryonic zebrafish. J Neurobiol 29:65-74.

Lee Y, Grill S, Sanchez A, Murphy-Ryan M, Poss KD (2005) Fgf signaling instructs position-dependent growth rate during zebrafish fin regeneration. Development 132:5173-5183.

Ludwin SK (1990) Oligodendrocyte survival in Wallerian degeneration. Acta Neuropathol 80:184-191.

Martini R (1994) Expression and functional roles of neural cell surface molecules and extracellular matrix components during development and regeneration of peripheral nerves. J Neurocytol 23:1-28.

Meyer RL (1982) Tetrodotoxin blocks the formation of ocular dominance columns in goldfish. Science 218:589-591.

Nasevicius A, Ekker SC (2000) Effective targeted gene 'knockdown' in zebrafish. Nat Genet 26:216-220.

Neuhauss SC, Biehlmaier O, Seeliger MW, Das T, Kohler K, Harris WA, Baier H (1999) Genetic disorders of vision revealed by a behavioral screen of 400 essential loci in zebrafish. J Neurosci 19:8603-8615.

Nguyen QT, Sanes JR, Lichtman JW (2002) Pre-existing pathways promote precise projection patterns. Nat Neurosci 5:861-867.

Oudega M, Xu XM (2006) Schwann cell transplantation for repair of the adult spinal cord. J Neurotrauma 23:453-467.

Pittman AJ, Law MY, Chien CB (2008) Pathfinding in a large vertebrate axon tract: isotypic interactions guide retinotectal axons at multiple choice points. Development 135:2865-2871.

Plachez C, Andrews W, Liapi A, Knoell B, Drescher U, Mankoo B, Zhe L, Mambetisaeva E, Annan A, Bannister L, Parnavelas JG, Richards LJ, Sundaresan V (2008) Robos are required for the correct targeting of retinal ganglion cell axons in the visual pathway of the brain. Mol Cell Neurosci 37:719-730.

Plump AS, Erskine L, Sabatier C, Brose K, Epstein CJ, Goodman CS, Mason CA, Tessier-Lavigne M (2002) Slit1 and Slit2 cooperate to prevent premature midline crossing of retinal axons in the mouse visual system. Neuron 33:219-232.

Reimer MM, Sörensen I, Kuscha V, Frank RE, Liu C, Becker CG, Becker T (2008) Motor neuron regeneration in adult zebrafish. J Neurosci $28: 8510-8516$.

Schmidt JT, Buzzard M, Borress R, Dhillon S (2000) MK801 increases retinotectal arbor size in developing zebrafish without affecting kinetics of branch elimination and addition. J Neurobiol 42:303-314.

Schweitzer J, Becker T, Becker CG, Schachner M (2003) Expression of protein zero is increased in lesioned axon pathways in the central nervous system of adult zebrafish. Glia 41:301-317.

Schweitzer J, Gimnopoulos D, Lieberoth BC, Pogoda HM, Feldner J, Ebert A, Schachner M, Becker T, Becker CG (2007) Contactinla expression is associated with oligodendrocyte differentiation and axonal regeneration in the central nervous system of zebrafish. Mol Cell Neurosci 35:194-207.

Stuermer CA, Bastmeyer M, Bähr M, Strobel G, Paschke K (1992) Trying to understand axonal regeneration in the CNS of fish. J Neurobiol 23:537-550.

Turner JE, Singer M (1974) The ultrastructure of regeneration in the severed newt optic nerve. J Exp Zool 190:249-268.

Westerfield M (1989) The zebrafish book: a guide for the laboratory use of zebrafish (Brachydanio rerio). Eugene: University of Oregon.

White FA, Behar O (2000) The development and subsequent elimination of aberrant peripheral axon projections in semaphorin3A null mutant mice. Dev Biol 225:79-86.

Xiao T, Roeser T, Staub W, Baier H (2005) A GFP-based genetic screen reveals mutations that disrupt the architecture of the zebrafish retinotectal projection. Development 132:2955-2967.

Yeo SY, Little MH, Yamada T, Miyashita T, Halloran MC, Kuwada JY, Huh TL, Okamoto H (2001) Overexpression of a slit homologue impairs convergent extension of the mesoderm and causes cyclopia in embryonic zebrafish. Dev Biol 230:1-17.

Yeo SY, Miyashita T, Fricke C, Little MH, Yamada T, Kuwada JY, Huh TL, Chien CB, Okamoto H (2004) Involvement of Islet-2 in the Slit signaling for axonal branching and defasciculation of the sensory neurons in embryonic zebrafish. Mech Dev 121:315-324. 